\title{
Evaluation of Treatment of Post Burn Atrophic Scars by Autologous Microfat Grafting
}

\author{
ASHRAF HUSSEIN ELGHAMRY, M.D.; WALEED ALDABAANY, M.D. and SHREIF MAHER, M.D. \\ The Department of Plastic Surgery, Faculty of Medicine, Fayoum University, Fayoum, Egypt
}

\begin{abstract}
Background: Atrophic scars are a cosmetically distressing problem for the patients especially post-burn ones as the patient seek both restoring volume contour and improving the quality of burn scar. To date there are no gold standards exist for the treatment of scar tissue. Autologous fat grafting has been introduced as a promising treatment option for scar tissue and its related symptoms. However, the scientific evidence for its effectiveness remains unclear. The aim of this study was to evaluate the effect of autologous microbat grafting on improving the aesthetic outcomes of post-burn atrophic scars.
\end{abstract}

Patients and Methods: This study was conducted on 20 patients with obvious post-burn atrophic scars at different body areas. Patients' age ranged from 16 to 35 years. The lower abdomen and inner thighs were the most commonly chosen donor sites. Microfat was processed by centrifugation to be injected directly under the scar tissue.

Results: Significant improvement was noticed in the pliability of scar with some improvements in pain and itching. No improvement was noticed regarding vascularity and pigmentation. Regarding patient satisfaction with cosmetic appearance, 8 cases were not satisfied and 12 cases were satisfied. However, most of patients (16 cases) were satisfied regarding restoration of volume contour.

Conclusion: Autologous microfat grafting has a minimal effect on improving the aesthetic outcomes of post-burn atrophic scars. On the other hand, it has a great effect on restoring the volume contour of the scars.

Key Words: Post-burn atrophic scars - Aesthetic outcomes - Microfat grafting.

\section{INTRODUCTION}

Trauma is the leading cause of death and disability in the first four decades of life and the third most common cause of death over the world. Burn trauma represents the second most common cause of trauma-related deaths [1].

A burn is a tissue injury caused by pathological energy. It may be chemical, thermal, electrical or radiation. It varies from small superficial burn up to major critical burns that threaten person's life leaving him disable, deformed and imprisoned in a scar [2].
Atrophic scars are broadly described as exhibiting generalized cutaneous atrophy resulting in loss of cutaneous cells in the epidermis although appear clinically as a loss of normal dermis [3].

There are various measures for atrophic scar treatment as ablative fractional laser therapy, nonablative laser therapy, dermabrasion, chemical peel therapy, surgical techniques such as subcision, injectables and combined therapy. All of them minimize scarring but not eliminate it completely [3].

A relatively new option for the treatment of scar tissue is the use of autologous fat grafting. The word "autologous fat grafting" means transferring of the patient's own fat from an area of the body (the donor site) to another area of the same body (the recipient site) [4].

Autologous fat grafting has a volume increasing effect and is thought to stimulate the neosynthesis of collagen fibers, which therefore increases the dermal thickness, resulting in an improvement of skin quality [5].

It has also shown improvement of different types of pain. The hypothesis is that mesenchymal cells of the graft give prolonged analgesia by changes in the microenvironment and secretion of substances [6].

Autologous fat tissue has been widely accepted in plastic and reconstructive surgery as an ideal filler for augmentation of soft tissue because it is biocompatible, versatile, natural appearing, non immunogenic, inexpensive and easily obtainable with low donor site morbidity [7].

The major obstacle is an unpredictable and often low graft survival, with resorption rates ranging from $25 \%$ to $70 \%$ of the total implanted volume, which may be partly related to insufficient vascularity of the transplant. Therefore, methods to increase graft viability are required [8]. 
Autologous fat grafting has been introduced as the treatment of atrophic scars and contour deformity. It not only serves to improve contour and to fill areas of deficiencies caused by trauma, deep burns or surgery, but increasingly there has been a focus on its ability to regenerate and remodel surrounding tissues [9].

\section{PATIENTS AND METHODS}

After approval of Research Ethical Committee of Faculty of Medicine, Fayoum University, this prospective study was performed at Plastic Surgery Unit, Fayoum University Hospital on 20 patients complained of post burn atrophic scars at different body areas in the period from February 2018 to March 2019. Those patients were subjected to one session of micro fat grafting conducting the same surgical technique to all of them.

All operations were performed under general anesthesia with the patient in the supine position.

\section{Surgical technique:}

\section{Infiltration:}

A small incision approximately $2 \mathrm{~mm}$ in size was made in the donor site using a number 11 blade through which a blunt multi-hole infiltration cannula was inserted to infiltrate the tumescent solution into the donor sites of fatty tissue removal. The mixture injected was prepared as follows: (1cc of adrenaline $1 \mathrm{mg} / \mathrm{ml}$ were added to 1000 of normal saline solution).

Then we waited about 10-15 minutes until the tumescent solution penetrated into the tissue to allow epinephrine to take full effect and provides good hemostasis.

\section{Fat harvesting:}

Donor areas as lower abdomen and thigh areas were chosen according to the amount of adipose tissue.

A multi-pores blunt tipped $3 \mathrm{~mm}$ harvesting cannula with several side holes of $1 \mathrm{~mm}$ in diameter attached to a $10 \mathrm{cc}$ Luer-Lock syringe was used to harvest the fat through the same incision made for infiltration of the mixture solution.

\section{Fat processing (refinement):}

The centrifugation method was used for processing of the harvested microfat. The aspirated fat was allowed to centrifuge in the same 10-cc syringes using a portable electric centrifuge at 3000 rpm for 3 minutes.
Centrifugation resulted in separation of material and formation of three layers:

A- At the top: An oily yellow layer which was an effect of ruptured fat cells.

B- In the middle: The adipose graft.

C- At the bottom: A red layer composed of serum, fluid and blood products.

The first and third layers were discarded away. The second layer was then transferred to several 1 cc Luer Lock syringes using a special connector with filter to transform the fat into micro fat. The syringes were then attached on the Luer-lock end to the fat injection cannula which was made ready for injection into the recipient site.

\section{Fat injection (placement):}

A blunt tipped $1.2 \mathrm{~mm}$ cannula with single side hole attached to a small 1cc Luer Lock syringe was used for fat injection.

Micro fat grafting was continued in multiple layers until the indicated volume of fat was added to each target area and no overcorrection was done in any case.

\section{Follow-up:}

Follow-up of the patients occurred at 2 weeks, 1 month, 3 months and 6 months post-operative. Results were compared by photographs all through, together with researcher's direct clinical evaluation.

\section{RESULTS}

During the study period (from February 2018 to March 2019) twenty patients with post-burn atrophic scars at different body areas were enrolled in this study. 18 females $(90 \%)$ and 2 male $(10 \%)$. Age ranged from 16 to 35 years with mean age 19.7 years. $60 \%$ of cases caused by scald burn (12 patients), $30 \%$ caused by flame burn (6 patients) and $10 \%$ caused by chemical burn (2 patient). $70 \%$ of them show scar on lower limb, $20 \%$ on head and neck, and $10 \%$ on upper limb. In $70 \%$ of patients the fat was harvested from lower abdomen and $30 \%$ of them from inner thighs.

The mean duration of scar was $(4.1 \pm 0.61)$ years ranged between 1 and 7 years. The mean amount of micro fat injection was (35.3 \pm 7.7$)$ cc ranged between 2 and $75 \mathrm{cc}$. As regards scar size the mean length of scar was $(8.7 \pm 2.5) \mathrm{cm}$ ranged between 2 and $30 \mathrm{~cm}$. and mean width was $(3.7 \pm 0.79) \mathrm{cm}$ ranged between 0.5 and $9 \mathrm{~cm}$.

Assessment of lesions was done by physician evaluation and by digital photos before and after 
treatment. The improvement was described according to scoring of 6 criteria (vascularity, pigmentation, pliability, surface appearance pain and itching).

Table (1) illustrates that there was no statistical significance difference with $p$-value $>0.05$ in the vascularity score at post-operative follow-up periods indicating no effect of microfat grafting on improving vascularity score.

Table (2) illustrates that there was no statistical significance difference with $p$-value $>0.05$ in the pigmentation score at post-operative follow-up periods indicating no effect of microfat grafting on improving pigmentation score.

Table (3) illustrates that there was improvement in the pliability score after 2 weeks and 1 month post-operative. There was no change after followup 6 months. $p$-value $<0.05$ was statistically significant indicating the positive effect of microfat grafting on improving pliability score.

Table (4) illustrates that there was minimal improvement after 2 weeks post-operative in the surface appearance score with no change after 1 month and 6 months post-operative. No statistical significance difference with $p$-value $>0.05$ indicating no effect of micro fat grafting on improving surface appearance score after 6 months postoperative.

Table (5) illustrates that there was improvement in the degree of itching after 2 weeks and 1 month post-operative then deterioration of response at 6 months post-operative. $p$-value $>0.05$ indicating that the overall improvement in itching score after follow-up 6 months was statistically not significant.

Table (6) illustrates that there was improvement in the degree of pain after 2 weeks and 1 month post-operative then deterioration of response at 6 months post-operative. $p$-value $>0.05$ indicating that the overall improvement in pain score, after follow-up 6 months, was statistically not significant.

Table (1): Comparison of vascularity score follow-up among study group.

\begin{tabular}{|c|c|c|c|c|c|}
\hline Vascularity score & $\begin{array}{l}\text { Before } \\
\text { No. }(\%)\end{array}$ & $\begin{array}{c}\text { After 2w } \\
\text { No. }(\%)\end{array}$ & $\begin{array}{c}\text { After } 1 \mathrm{~m} \\
\text { No. }(\%)\end{array}$ & $\begin{array}{c}\text { After } 6 \mathrm{~m} \\
\text { No. }(\%)\end{array}$ & $\begin{array}{c}p- \\
\text { value }\end{array}$ \\
\hline 0: Normal color & $10(50 \%)$ & $10(50 \%)$ & $10(50 \%)$ & $10(50 \%)$ & 0.1 \\
\hline 1: Pink & $8 \quad(40 \%)$ & $8 \quad(40 \%)$ & $8 \quad(40 \%)$ & $8 \quad(40 \%)$ & \\
\hline 2: Red & $2(10 \%)$ & $2(10 \%)$ & $2(10 \%)$ & $2(10 \%)$ & \\
\hline
\end{tabular}

Table (2): Comparison of pigmentation score follow-up among study group.

\begin{tabular}{|c|c|c|c|c|c|}
\hline Pigmentation score & $\begin{array}{c}\text { Before } \\
\text { No. }(\%)\end{array}$ & $\begin{array}{l}\text { After } 2 \mathrm{w} \\
\text { No. }(\%)\end{array}$ & $\begin{array}{c}\text { After } 1 \mathrm{~m} \\
\text { No. }(\%)\end{array}$ & $\begin{array}{l}\text { After } 6 \mathrm{~m} \\
\text { No. }(\%)\end{array}$ & $\begin{array}{c}p^{-} \\
\text {value }\end{array}$ \\
\hline 0: Normal color & $0(0.0 \%)$ & $0(0.0 \%)$ & $0(0.0 \%)$ & $0(0.0 \%)$ & 0.1 \\
\hline $\begin{array}{l}\text { 1: Hypopigmen- } \\
\text { tation }\end{array}$ & $5(25 \%)$ & $5(25 \%)$ & $5(25 \%)$ & $5(25 \%)$ & \\
\hline $\begin{array}{l}\text { 2: Mixed pigmen- } \\
\text { tation }\end{array}$ & $9(45 \%)$ & $9(45 \%)$ & $9(45 \%)$ & $9(45 \%)$ & \\
\hline $\begin{array}{l}\text { 3: Hyperpigmen- } \\
\text { tation }\end{array}$ & $6(30 \%)$ & $6(30 \%)$ & $6(30 \%)$ & $6(30 \%)$ & \\
\hline
\end{tabular}

Table (3): Comparison of pliability score follow-up among study group.

\begin{tabular}{|c|c|c|c|c|c|}
\hline Pliability score & $\begin{array}{l}\text { Before } \\
\text { No. }(\%)\end{array}$ & $\begin{array}{c}\text { After } 2 \mathrm{w} \\
\text { No. }(\%)\end{array}$ & $\begin{array}{c}\text { After } 1 \mathrm{~m} \\
\text { No. }(\%)\end{array}$ & $\begin{array}{c}\text { After } 6 \mathrm{~m} \\
\text { No. }(\%)\end{array}$ & $\begin{array}{c}p- \\
\text { value }\end{array}$ \\
\hline 0: Normal & - & $2(10 \%)$ & $2(10 \%)$ & $2(10 \%)$ & $0.003 *$ \\
\hline 1: Supple(flexible with minimal resistance) & $2(10 \%)$ & $6(20 \%)$ & $6(30 \%)$ & $6(30 \%)$ & \\
\hline 2: Yielding (moderate resistance) & $6(30 \%)$ & $10(50 \%)$ & $8(40 \%)$ & $8(40 \%)$ & \\
\hline 3: Firm (inflexible, resistant to manual pressure) & $8(40 \%)$ & $4(20 \%)$ & $4(20 \%)$ & $4(20 \%)$ & \\
\hline 4: Banding (rope-like tissue that blanches with extension of the scar) & $4(20 \%)$ & - & - & - & \\
\hline
\end{tabular}

Table (4): Comparison of surface appearance score followup among study group.

\begin{tabular}{llllll}
\hline $\begin{array}{l}\text { Surface appearance } \\
\text { score }\end{array}$ & $\begin{array}{c}\text { Before } \\
\text { No. }(\%)\end{array}$ & $\begin{array}{c}\text { After 2w } \\
\text { No. (\%) }\end{array}$ & $\begin{array}{c}\text { After 1m } \\
\text { No. (\%) }\end{array}$ & $\begin{array}{c}\text { After 6m } \\
\text { No. (\%) }\end{array}$ & $\begin{array}{c}p \text { - } \\
\text { value }\end{array}$ \\
\hline $\begin{array}{l}\text { 1: Similar to normal } \\
\text { 2: Slight mismatch }\end{array}$ & $8(0 \%)$ & $2(10 \%)$ & $2(10 \%)$ & $2(10 \%)$ & 0.6 \\
$\begin{array}{l}\text { 3: Noticeably } \\
\quad \text { rougher }\end{array}$ & $8(40 \%)$ & $8(40 \%)$ & $8(40 \%)$ & $8(40 \%)$ & \\
4: Very rough & $4(20 \%)$ & $4(20 \%)$ & $4(20 \%)$ & $4(20 \%)$ & \\
\hline
\end{tabular}

Table (5): Comparison of itching score follow-up among study group.

\begin{tabular}{|c|c|c|c|c|c|}
\hline Itching score & $\begin{array}{l}\text { Before } \\
\text { No. }(\%)\end{array}$ & $\begin{array}{c}\text { After } 2 \mathrm{w} \\
\text { No. }(\%)\end{array}$ & $\begin{array}{l}\text { After 1m } \\
\text { No. }(\%)\end{array}$ & $\begin{array}{l}\text { After } 6 \mathrm{~m} \\
\text { No. }(\%)\end{array}$ & $\begin{array}{c}p- \\
\text { value }\end{array}$ \\
\hline 0: No itching & $2(10 \%)$ & $4(20 \%)$ & $12(60 \%)$ & $8(40 \%)$ & 0.2 \\
\hline 1: Sometime itchy & $15(75 \%)$ & $14(70 \%)$ & $6(30 \%)$ & $9(45 \%)$ & \\
\hline $\begin{array}{l}\text { 2: Occasionally, } \\
\text { tolerable }\end{array}$ & $3 \quad(15 \%)$ & $2(10 \%)$ & $2(10 \%)$ & $3(15 \%)$ & \\
\hline
\end{tabular}

Table (6): Comparison of pain score follow-up among study group.

\begin{tabular}{llllll}
\hline Pain score & $\begin{array}{c}\text { Before } \\
\text { No. }(\%)\end{array}$ & $\begin{array}{c}\text { After 2w } \\
\text { No. }(\%)\end{array}$ & $\begin{array}{c}\text { After 1m } \\
\text { No. }(\%)\end{array}$ & $\begin{array}{c}\text { After 6m } \\
\text { No. (\%) }\end{array}$ & $\begin{array}{c}p \text { - } \\
\text { value }\end{array}$ \\
\hline 0: No pain & $8(40 \%)$ & $12(60 \%)$ & $16(80 \%)$ & $12(60 \%)$ & 0.08 \\
1: Sometimes painful & $10(50 \%)$ & $8(40 \%)$ & $4(2 \%)$ & $8(40 \%)$ & $0(0 \%)$ \\
2: Moderately irritable pain & $2(10 \%)$ & $0(0 \%)$ & $0(0 \%)$ & $0 \quad(0)$ \\
\hline
\end{tabular}



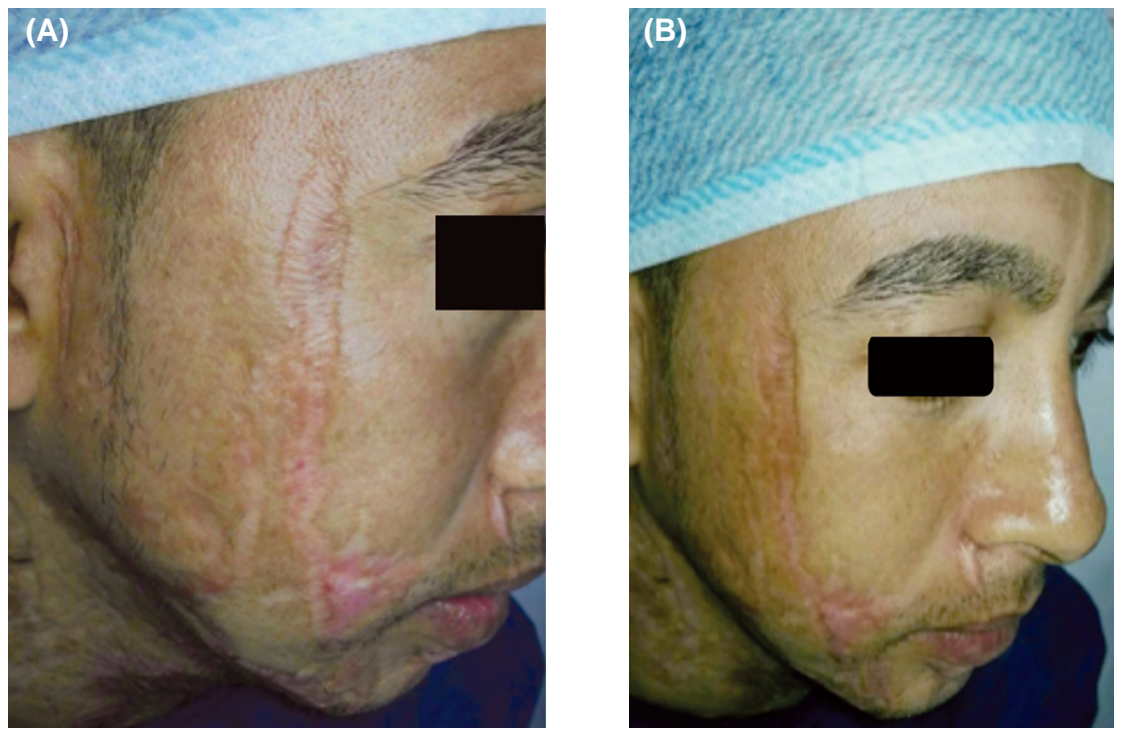

Fig. (1): (A,B): Pre-operative views of post-burn atrophic scar over the right cheek (A: Right lateral view \& B: Right oblique).
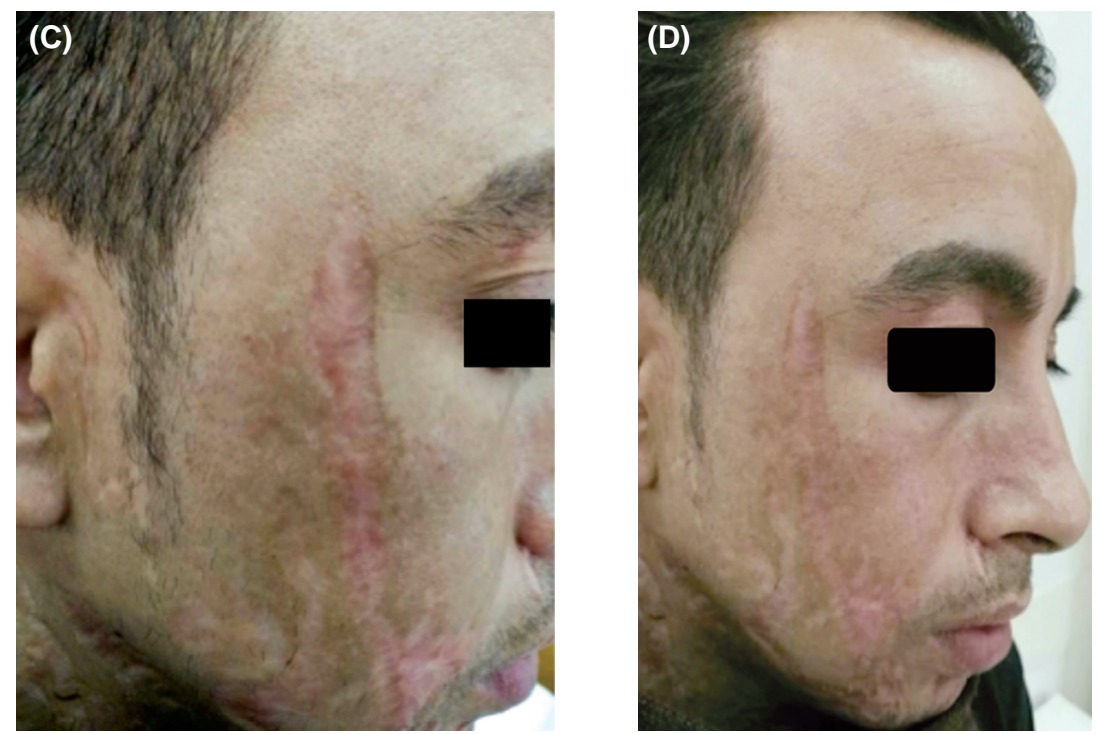

Fig. (1): (C,D): Outcome 6 months post-operatively (C: Right lateral view \& D: Right oblique view).
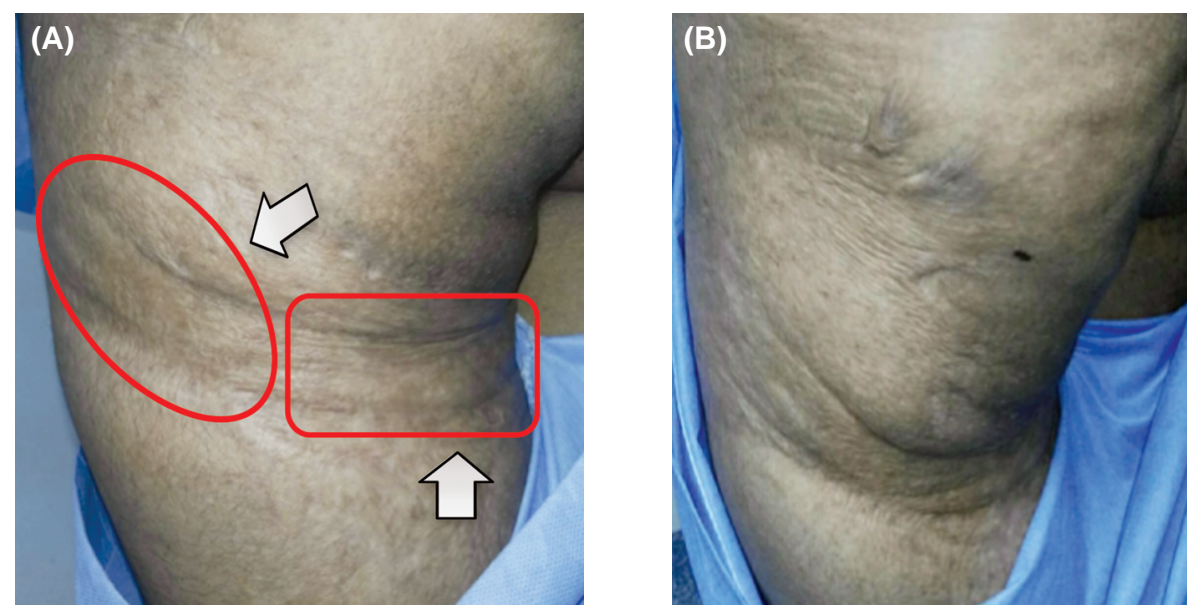

Fig. (2): (A,B): Pre-operative views of post-burn atrophic depressed scar over the posterior surface of upper part of left thigh (A: Posterior view with pre-operative marking \& B: Left lateral view). 

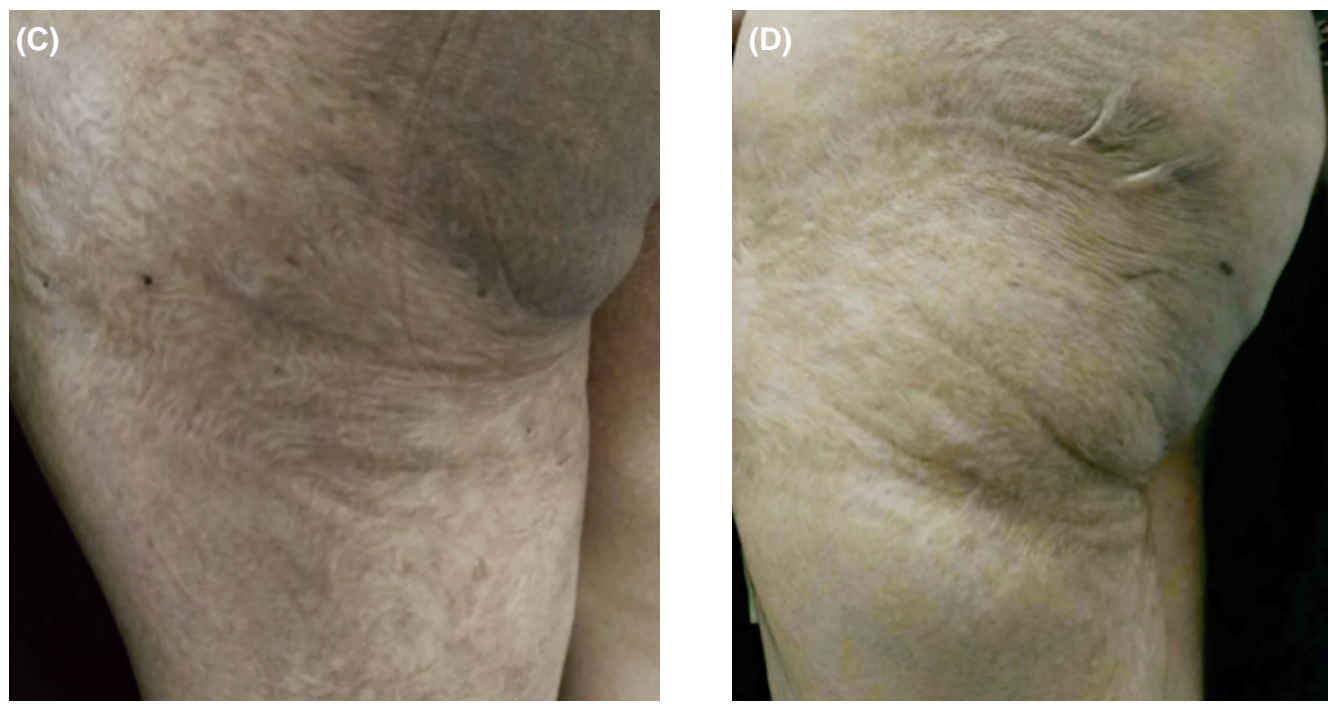

Fig. (2): (C,D): Outcome 6 months post-operatively (C: Posterior view \& D: Left lateral view).
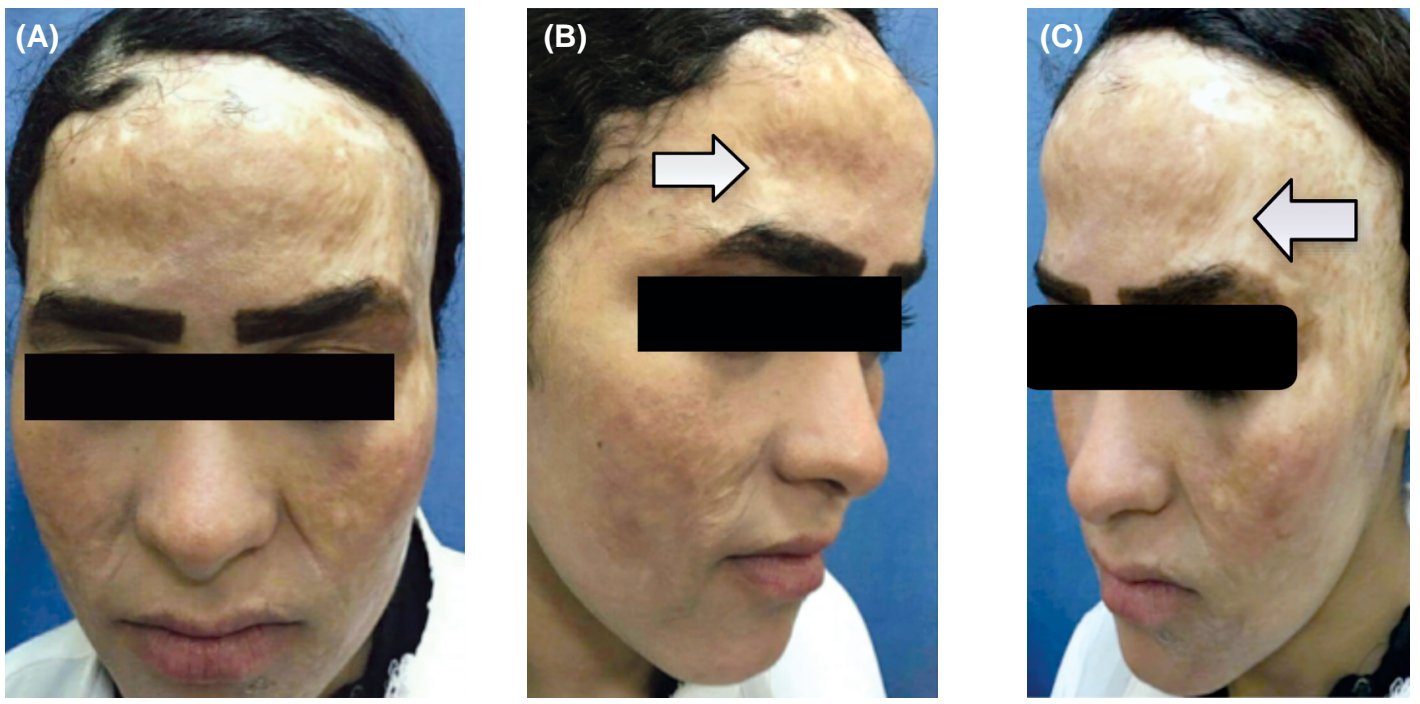

Fig. (3): (A,B,C): Pre-operative views of two post-burn atrophic depressed scars over the forehead (A: Frontal view \& B: Right oblique view \& C: Left oblique view).
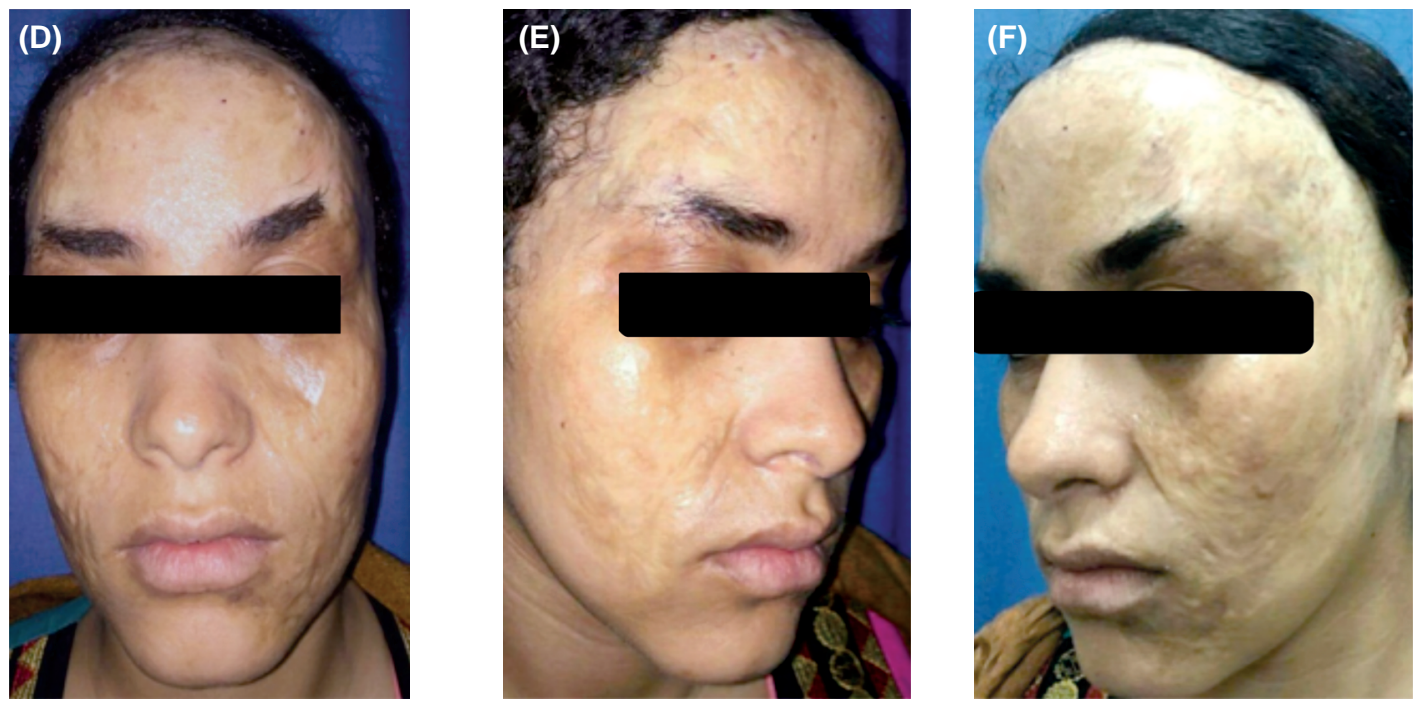

Fig. (3): (D,E,F): Outcome 6 months post-operatively (D: Frontal view, E: Right oblique view \& F: Left oblique view). 


\section{DISCUSSION}

For post burn scar treatment autologous fat graft and its regenerative properties has proved to be a new possible chance for scar treatment [10].

The major advantages of autologous fat grafting are as follows: Minimally invasive operation, short hospital stay, ease of harvest and implantation, low donor site morbidity, availability of fat and autologous nature, easy to learn and practice, and minimal complications in competent hands [11].

The major obstacle is an unpredictable and often low graft survival, with resorption rates ranging from $25 \%$ to $70 \%$, which may be partly related to insufficient vascularity of the transplant [12].

In the current study, the centrifugation method was used for processing of the harvested micro fat. No decantation of the harvested fat was performed in our study.

In agreement with that, Conde-Green et al., compared the content of adipocytes and mesenchymal stem cells of fat grafts processed by decantation or centrifugation. Although there are significantly more viable adipocytes in the decanted group, the fat grafts processed with decantation still contain a great quantity of contaminating blood cells and fewer stem cells [13].

In this study we evaluated the effect of micro fat grafting on improving the quality and cosmetic appearance of post-burn atrophic scars assessing 4 parameters of scar quality (vascularity, pigmentation, pliability and surface appearance) via a subjective aesthetic scar evaluation scale and we also evaluated its effect on improving scar-related symptoms (pain and itching) with post-operative follow-up periods as follows: At 2 weeks, 1 month and 6 months.

Regarding vascularity and pigmentation, there were no statistical significance difference at postoperative follow-up periods with $p$-value $=1.000$ (NS) indicating that is no effect of micro fat grafting on improving the vascularity and pigmentation scores.

The main improvement was noticed in the pliability score which was statistically significant after 2 weeks post-operative with $p$-value $=0.001$ (S). Further improvement was noticed after 1 month post-operative which was statistically not significant, $p$-value $=0.3$ (NS). There was no significant changes after 6 months post-operative with $p$-value $=1.000(\mathrm{NS})$.
Regarding surface appearance, there was minimal improvement after 2 weeks post-operative which was statistically not significant, $p$-value $=$ 0.3 (NS). There was no significant changes after 1 month and after 6 months post-operative with $p$ value $=1.000(\mathrm{NS})$.

From the above results regarding the 4 parameters of scar quality, we can notice that micro fat has improved only the pliability of scars with no improvement noticed in other parameters (vascularity, pigmentation and surface appearance).

In agreement with these results, Sardesai and Moore performed a study on fourteen patients with various scar types treated with subdermal micro fat grafting over 30 months. Dermal elasticity, vascularity, pigmentation, pliability, patient perception and satisfaction and observer assessment of scar characteristics were evaluated preoperatively and 1 year after treatment with validated objective and subjective measures.

Sardesai and Moore concluded that microfat grafting improved certain dermal characteristics including elasticity, skin thickness, stiffness, and pliability as evaluated by quantitative and validated qualitative measures. Microfat grafting of cutaneous scars did not appear to affect skin color (vascularity $\&$ pigmentation) [14].

On the contrary, Brongo et al., performed fat grafting on 18 patients with post-burn hypertrophic scars and keloids, three times at 3-month interval, noting better color, texture, thickness, elasticity and a reduction of scar retraction at 1 year after treatment [15].

Also, Klinger et al., concluded that injection of processed autologous fat seems to be a promising and effective therapeutic approach to scars of different origin, and they confirmed that the treated areas regain characteristics similar to normal skin, with not only aesthetic but also functional results. The treated skin becomes more elastic and softer with significant improvement of color, shape, thickness and movement was seen as early as 3 months post-operatively. Durometer evaluation data showed a significant reduction in skin hardness after autologous fat grafting, which demonstrates efficacy in scar treatment [16].

Regarding itching, there was improvement after 2 weeks post-operative which was statistically not significant, $p$-value $=0.2$ (NS). Further improvement (accumulative effect) was noticed after 1 month post-operative which was statistically significant, 
$p$-value $=0.03(\mathrm{~S})$. Recurrence of itching was noticed after 6 months post-operative in $37.5 \%$ of cases with $p$-value $=0.09$ (NS).

Regarding pain, there was improvement after 2 weeks post-operative which was statistically not significant, $p$-value $=0.08$ (NS). Further improvement was noticed after 1 month post-operative which was statistically not significant too, $p$-value $=0.3$ (NS). Recurrence of pain was noticed after 6 months post-operative in $50 \%$ of cases with $p$ value $=0.2(\mathrm{NS})$.

From the above results regarding scar-related symptoms (pain and itching), we can notice that micro fat has some degree of improvement on pain $\&$ itching.

In agreement with these results, Fredman et al., focused on the improvement of neuropathic pain on 7 patients with chronic, refractory neuropathic pain, who underwent fat grafting to burn scars and also reported improvement of color, texture, contour, pliability and itching. Six of seven patients had improvement in neuropathic pain after fat grafting [17].

Also, Klinger et al., reported reduction in the degree of pain in 376 patients with retractile and painful scars of different origin treated with lipofilling but there was no reduction in the degree of itching after 12 months [16].

From all of the above results in the current study, we can notice that the improvement in the total score of aesthetic outcomes after 6 months follow-up in comparison with the pre-operative state with was mainly due to the improvement noticed in the pliability of scar plus improvements noticed in pain and itching.

In the current study, we can notice that microfat grafting was superior in post-burn atrophic scars as a good volume filler because of its filling character rather than its minimal effect on improving the quality of scars through improvement in the pliability score only plus some improvement in pain and itching.

\section{Conclusion:}

Micro fat has shown a significant improvement in the pliability of scars, with maximum improvement was after 2 weeks post-operative.

Also, some insignificant improvement was noticed in pain and as regarding itching, there was insignificant improvement after 2 weeks postoperative and became significant after 1 month post-operative.
On the other hand, there was no improvement noticed in other parameters of scar quality (vascularity, pigmentation and surface appearance).

Therefore, our clinical study concluded that autologous micro fat grafting has a minimal effect on improving the aesthetic outcomes of post-burn atrophic scars and scar-related symptoms (pain \& itching) and much more great effect on restoring volume contour and filling areas of volume deficits of theses scars especially the depressed ones.

\section{REFERENCES}

1- Hawkins H.K. and Pereira C.T.: Pathophysiology of the burn scar. In: Herndon DN, editor: Total Burn Care. $3^{\text {rd }}$ edn, Saunders Elsevier (Philadelphia), 608-19, 2007.

2- Burd A.: Burns: Treatment and Outcomes. Seminars in Plastic Surgery, 24 (03): 262-80, 2010.

3- Patel L., McGrouther D. and Chakrabarty K.: Evaluating evidence for atrophic scarring treatment modalities. JRSM Open, 5 (9), 2014.

4- Negenborn V., Groen J., Smit J., Niessen F. and Mullender M.: The Use of Autologous Fat Grafting for Treatment of Scar Tissue and Scar-Related Conditions. Plastic and Reconstructive Surgery, 137 (1): 31-43, 2016.

5- Simonacci F., Bertozzi N., Grieco M., Grignaffini E. and Raposio E.: Procedure, applications and outcomes of autologous fat grafting. Annals of Medicine and Surgery, 20: 49-60, 2017.

6- Herold C., Fleischer O. and Allert S.: Autologous fat injection for treatment of carpometacarpal joint osteoarthritis of the thumb-a promising alternative. Handchir Mikrochir. Plast. Chir., 46: 108-12, 2014.

7- Zielins R., Brett A., Longaker T. and Wan C.: Autologous Fat Grafting: The Science Behind the Surgery. Aesthetic Surgery Journal, 36 (4): 488-96, 2016.

8- Bellini E., Grieco M. and Raposio E.: The science behind autologous fat grafting. Annals of Medicine and Surgery, 24: 65-73, 2017.

9- Lee G., Hunter-Smith D. and Rozen W.: Autologous fat grafting in keloids and hypertrophic scars: A review. Scars, Burns \& Healing, 2017.

10- Klinger M., Klinger F. and Lisa A.: Regenerative approach to scars, ulcers and related problems with fat grafting. Clin. Plastic Surg., 2015.

11- Kaminer M.S. and Omura N.E.: Autologous fat transplantation. Arch. Dermatol., 137: 812-4, 2001.

12- Bellini E., Grieco M. and Raposio E.: The science behind autologous fat grafting. Annals of Medicine and Surgery, 24: 65-73, 2017.

13- Condé-Green A., Baptista L.S., De Amorin N.F.: Effects of centrifugation on cell composition and viability of aspirated adipose tissue processed for transplantation. Aesthet. Surg. J., 30: 249-55, 2010.

14- Sardesai M. and Moore C.: Quantitative and qualitative dermal change with microfat grafting of facial scars. Otolaryngology-Head and Neck Surgery, 137 (6): 86872, 2007. 
15- Brongo S., Nicoletti G.F., La Padula S., Mele C.M. and D'Andrea F.: Use of lipofilling for the treatment of severe burn outcomes. Plast. Reconstr. Surg., 130: 3746, 2012.

16- Klinger M., Caviggioli F., Klinger F., et al.: Autologous fat graft in scar treatment. J. Craniofac. Surg., 24: 16105, 2013.

17- Fredman R., Edkins R.E. and Hultman C.S.: Fat grafting for neuropathic pain after severe burns. Ann. Plast. Surg., 76: 295-303, 2016. 